\title{
Performance of Molecular Approaches for Aspergillus Detection and Azole Resistance Surveillance in Cystic Fibrosis
}

OPEN ACCESS

Edited by:

Helmut J. F. Salzer,

Forschungszentrum Borstel (LG),

Germany

Reviewed by:

Ralf Bialek,

LADR GmbH, Germany

Ana Alastruey-Izquierdo,

Instituto de Salud Carlos III, Spain

${ }^{*}$ Correspondence:

Jean-Pierre Gangneux jean-pierre.gangneux@univ-rennes1.fr

Specialty section:

This article was submitted to Fungi and Their Interactions,

a section of the journal

Frontiers in Microbiology

Received: 17 January 2018 Accepted: 08 March 2018

Published: 27 March 2018

Citation:

Guegan H, Chevrier S, Belleguic $C$,

Deneuville $E$, Robert-Gangneux $F$ and Gangneux J-P (2018)

Performance of Molecular Approaches for Aspergillus Detection and Azole Resistance Surveillance in Cystic Fibrosis.

Front. Microbiol. 9:531. doi: 10.3389/fmicb.2018.00531

\author{
Hélène Guegan ${ }^{1}$, Sylviane Chevrier ${ }^{1}$, Chantal Belleguic ${ }^{2}$, Eric Deneuville $^{3}$, \\ Florence Robert-Gangneux ${ }^{1,4}$ and Jean-Pierre Gangneux ${ }^{1,4 *}$
}

${ }^{1}$ Laboratoire de Parasitologie-Mycologie, Centre Hospitalier Universitaire de Rennes, Rennes, France, ${ }^{2}$ Centre de Ressources et de Compétences de la Mucoviscidose Adulte, Centre Hospitalier Universitaire de Rennes, Rennes, France, ${ }^{3}$ Centre de Ressources et de Compétences de la Mucoviscidose Pédiatrique, Centre Hospitalier Universitaire de Rennes, Rennes, France, ${ }^{4}$ Université de Rennes 1, INSERM, Institut de Recherche en Santé, Environnement et Travail - UMR_S 1085, Rennes, France

Aspergillus fumigatus triazole resistance is an emerging concern for treating chronically infected/colonized patients. This study sought to evaluate the performance of PCR assays to detect Aspergillus fungi together with azole resistance in sputum samples from cystic fibrosis (CF) patients. In total, 119 sputum samples from 87 CF patients were prospectively processed for Aspergillus detection by means of mycological culture and four QPCR assays, 2 in-house methods and two commercial multiplex real-time PCR assays simultaneously detecting Aspergillus and the most relevant cyp51A gene mutations (MycoGENIE ${ }^{\circledR}$ and AsperGenius ${ }^{\circledR}$ ). Azole susceptibility of $A$. fumigatus isolates was assessed using Etest ${ }^{\circledR}$ method and cyp51A gene mutation were characterized by sequencing. The overall rate of Aspergillus detection with the four QPCR assays ranged from 47.9 to $57.1 \%$, contrasting with $42 / 119$ (35.3\%) positive cultures with $A$. fumigatus. The high sensitivity of PCR on sputum could then contribute to more effective grading of Aspergillus disease in CF patients. Five out of 41 isolated strains (12.2\%) exhibited azoleresistant MIC patterns, three of which harbored cyp51A mutations and only $1 / 3$ with the sequence $\mathrm{TR}_{34} / \mathrm{L} 98 \mathrm{H}$. Combined with culture, $\mathrm{PCR}$ assay achieved high sensitivity Aspergillus screening in CF samples. However, cyp51A targeting was only moderately effective for azole resistance monitoring, while Aspergillus resistance remains of great concern.

Keywords: Aspergillus, aspergillosis, cystic fibrosis, quantitative real-time PCR, azole resistance, sputum

\section{INTRODUCTION}

Aspergillus fumigatus is responsible for severe asthma or allergic bronchopulmonary aspergillosis (ABPA) in up to 15\% of cystic fibrosis (CF) patients (Stevens et al., 2003; Pihet et al., 2009), though the significance of its detection is often questioned when there are no accompanying clinical signs. A. fumigatus is usually susceptible to triazole antifungal drugs (with the exception of fluconazole), which have proved beneficial in treating chronic pulmonary aspergillosis (CPA). During ABPA and chronic colonization, however, their use is still controversial (Stevens et al., 2003; Pihet et al., 2009). 
Over the last decade, A. fumigatus resistant isolates to triazole have been increasingly reported, and proven associated with a markedly higher mortality rate (van der Linden et al., 2011). This decreased susceptibility is primarily due to mutations in the cyp51A gene encoding lanosterol $14 \alpha$-demethylase, the enzyme involved in ergosterol biosynthesis (Mellado et al., 2001; Alcazar-Fuoli and Mellado, 2013). While $\mathrm{TR}_{34} / \mathrm{L} 98 \mathrm{H}$ and $\mathrm{TR}_{46} / \mathrm{Y} 121 \mathrm{~F} / \mathrm{T} 289 \mathrm{~A}$ alterations account for the majority of azole resistance cases, a large diversity of cyp51A mutations has also been associated with resistance (Verweij et al., 2016). Mutations have been thought to arise during prolonged antifungal therapy or prophylaxis in individual patients, yet a number of these mutated strains were cultured from patients with no previous azole exposure. Recent data suggest that the proliferating resistance is also caused by intensive use of azole fungicides in agriculture (Verweij et al., 2016). In France, the prevalence of resistant $A$. fumigatus strains grown from sputum samples of CF patients is particularly high, ranging from 4.6 to $10.6 \%$ (Burgel et al., 2012; Morio et al., 2012). On the other hand, the current prevalence of triazole resistance in immunocompromised patients with invasive aspergillosis (IA) still remains low, estimated at $\leq 1 \%$ in France (Alanio et al., 2011; Guegan et al., 2018).

In vitro antifungal susceptibility testing is thus essential for patient management. In routine practice, the detection of azole resistance is primarily based on the in vitro determination of minimum inhibitory concentration (MIC) from isolates. However, the data on A. fumigatus resistance are scarce as susceptibility testing is not always routinely performed and sputum culture lacks sensitivity. To overcome these limitations in resistance screening, molecular methods have recently been developed to detect $A$. fumigatus cyp51A gene mutations, primarily in clinical specimens. Several nested PCR assays (van der Linden et al., 2010; Denning et al., 2011; Spiess et al., 2012, 2014) and commercial kits have previously been used, such as Aspergenius ${ }^{\circledR}$ (Chong et al., 2015; White et al., 2015) and Mycogenie $^{\circledR}$ (Dannaoui et al., 2017) targeting both Aspergillus and key cyp51A alterations associated with azole resistance, though they have yet to be evaluated in field studies, particularly involving patients with chronic infection.

In this study, we prospectively investigated the prevalence of Aspergillus and the triazole resistance of A. fumigatus in sputum samples from CF patients using both phenotypic and molecular approaches. The efficacy of two commercial multiplex PCR assays AsperGenius ${ }^{\circledR}$ (PathoNostics, Maastricht, Netherlands) and Mycogenie ${ }^{\circledR}$ (Ademtech, Pessac, France) were compared with two real-time in-house Aspergillus assays as well as cultures. The ability of these PCR assays to detect Aspergillus and resistance markers was compared with culture-based susceptibility testing and subsequent cyp51A gene sequencing.

\section{MATERIALS AND METHODS}

\section{Population}

Over a 6-month period, (December 2015-May 2016), all expectorated sputum samples collected from CF patients as part of their routine quarterly follow-up at the Centre de Ressources et de Compétences de la Mucoviscidose at Rennes University Hospital (France) were included. The samples were processed for all methods each time the minimum sample volume $(\geq 1 \mathrm{ml})$ was available.

\section{Sputum Culture}

On reception, 1-2 $\mathrm{mL}$ of sputum were digested with $1 \mathrm{X}$ DigestEUR $^{\circledR}$, Eurobio (ratio: 1:1), and homogenized for $30 \mathrm{~min}$ at room temperature. Samples were divided into two aliquots to perform fungal culture and PCR assays, respectively.

For the cultures, $100 \mu \mathrm{L}$ of pellets were inoculated in two plates of fungal media (Sabouraud dextrose agar supplemented with $0.5 \%$ chloramphenicol). One was incubated at $30^{\circ} \mathrm{C}$ and the other at $37^{\circ} \mathrm{C}$ for 7 days (Borman et al., 2010). Mold types isolated from the cultures were identified by microscope.

\section{DNA Extraction From Sputum Samples}

We extracted $1 \mathrm{~mL}$ of digested sputum for centrifugation, and DNA was extracted from a $200 \mu \mathrm{L}$ pellet using the QIAamp ${ }^{\circledR}$ DNA Mini Kit (Qiagen) following overnight incubation with proteinase $\mathrm{K}$, according to the manufacturer's instructions. As an extraction control, $10 \mu \mathrm{L}$ of viral DNA (DiaControlDNA, Diagenode) were added. Elution was performed in $100 \mu \mathrm{L}$, and the extracted DNA was stored at $-20^{\circ} \mathrm{C}$ until PCR testing.

\section{Susceptibility Testing}

Each A. fumigatus isolate recovered from Sabouraud slants was tested as an individual isolate using itraconazole (ITC) and voriconazole (VRC) Etest ${ }^{\circledR}$ strips (Biomérieux, Marcy-L'Etoile, France). MICs were determined following $48 \mathrm{~h}$ incubation at $37^{\circ} \mathrm{C}$. Posaconazole (POS) susceptibility was also tested using Etest $^{\circledR}$ method, only for strains with decreased susceptibility to ITC or VRC. Strains with MIC $>2 \mathrm{mg} / \mathrm{L}$ for ITC and VRC, and $>0.25 \mathrm{mg} / \mathrm{L}$ for POS, were considered resistant, according to recent EUCAST breakpoints for fungi (European Committee on Antimicrobial Susceptibility Testing [EUCAST], 2017).

\section{In-House Aspergillus PCR Assays}

Sputum DNA extracts were tested using two real-time "in-house" PCR assays for Aspergillus detection.

The first PCR assay ("Af-mito") amplified a 196 bpsequence of $A$. fumigatus mitochondrial gene, as previously described (F: GAAAGGTCAGGTGTTCGAGTCA; R: CATC ATGAGTGGTCCGCTTTAC; 5'FAM and 3'TAMRA-labeled probe 5'-ATCCCTAAACCCGCAACCAAAGGC) (Bretagne et al., 1995).

The second PCR assay (" $28 \mathrm{~S}$ ") targeted a $67 \mathrm{bp}$-fragment of the A. fumigatus $28 S$ rRNA gene, employing the primers and probe used by Challier et al. (2004) (28S-466: CTCG GAATGTATCACCTCTCGG; 28S-533: TCCTCGGTCCAGG CAGG; 28S-490: FAM-TGTCTTATAGCCGAGGGTGCAATGC G-TAMRA).

Each amplification was performed in a $25 \mu \mathrm{L}$ final volume containing 1X TaqMan ${ }^{\circledR}$ Universal PCR MasterMix, $0.5 \mu \mathrm{M}$ 
of each primer, $0.2 \mu \mathrm{M}$ of probe, $2.5 \mu \mathrm{L}$ of mix for internal control amplification (DiaControlDNA, Diagenode), and $5 \mu \mathrm{L}$ of sampled DNA.

Amplification was performed in the following thermal conditions: $2 \mathrm{~min}$ at $50^{\circ} \mathrm{C}, 10 \mathrm{~min}$ at $95^{\circ} \mathrm{C}$, and 45 cycles of $15 \mathrm{~s}$ at $95^{\circ} \mathrm{C}$, then $1 \mathrm{~min}$ at $60^{\circ} \mathrm{C}$, all on a StepOne Plus ${ }^{\circledR}$ instrument (Applied Biosystems).

\section{Commercial Aspergillus PCR Assays}

Sputum specimens were analyzed by means of two commercial multiplex real-time PCR assays simultaneously detecting Aspergillus and the most relevant cyp51A gene mutations.

MycoGENIE $^{\circledR}$ (AdemTech, Pessac, France) is a quadruplex real-time PCR assay which targets A. fumigatus (28SrRNA multicopy gene) in the $\mathrm{TR}_{34}$ and $\mathrm{L} 98 \mathrm{H}$ regions of the single-copy cyp51A gene, including an internal control to monitor for sample inhibition. Amplification was performed over 45 cycles, using an LC480 PCR device (Roche, Meylan, France). When the A. fumigatus target was negative and the $C t$ value $>35$ for IC amplification, or when results contrasted with those of the in-house PCRs, the samples were retested, diluted to 1:10, 1:20, and 1:50.

AsperGenius $^{\circledR}$ assay (PathoNostics, Maastricht, Netherlands) provides two different real-time quadruplex amplification mixtures, one for the detection of Aspergillus species, and the other one for identifying prevalent resistance mutations. The species multiplex assay enables specific detection of the A. fumigatus complex (Af), A. terreus, and Aspergillus sp. (Asp sp.), by targeting the $28 S$ rRNA multicopy gene. Samples were retested diluted to $1: 10$ if the internal control $C t$ was $>36$. The resistance multiplex assay targets the single-copy cyp51A gene of A. fumigatus, and can detect the $\mathrm{TR}_{34}, \mathrm{~L} 98 \mathrm{H}$, $\mathrm{Y} 121 \mathrm{~F}$, and T289A regions. Distinction between wild-type and mutant A. fumigatus strains was performed by melting curve analysis. The differences in fusion temperatures necessary to assign resistance were interpreted following the manufacturer's instructions.

Amplification was performed over 45 cycles, according to the manufacturer's instructions, on a LightCycler ${ }^{\circledR} 480$ instrument (Roche). Analysis was performed on the LightCycler ${ }^{\circledR} 480$ software, using the second derivative function. The horizontal threshold was fixed above background noise and a positive result was defined by a signal detection with a $\mathrm{Ct}$ value $<45$ cycles.

\section{DNA Extraction From Resistant \\ A. fumigatus Strains}

DNA was extracted from A. fumigatus cultures a minimum of 4 days old. A conidial suspension was created in MagNA ${ }^{\circledR}$ Pure Bacteria Lysis Buffer (Roche) and transferred to a MagNa ${ }^{\circledR}$ Lyser Green Beads tube (Roche) for homogenization with the $\mathrm{MagNa}^{\circledR}$ Lyser Instrument (Roche). We then extracted $400 \mu \mathrm{L}$ of supernatant using the $\mathrm{MagNa}^{\circledR}$ Pure Compact Nucleic Acid Isolation Kit and a $\mathrm{MagNa}^{\circledR}$ Pure Extraction Instrument (Roche Diagnostics), according to the manufacturer's instructions.

\section{Molecular Identification of Resistant Strains}

Identification of A. fumigatus isolates with ITC MIC $>2 \mathrm{mg} / \mathrm{L}$ was further confirmed by beta-tubulin gene sequencing.

PCR amplification was performed using $B t 2 a$ and $B t 2 b$ primers (Glass and Donaldson, 1995). Amplification reaction and subsequent sequencing were performed as previously described (Comacle et al., 2016). Sequencing was performed using an ABI PRISM ${ }^{\otimes} 3130$ Genetic Analyzer (Applied Biosystems). Bidirectional sequences were analyzed using Seqscape ${ }^{\circledR}$ software v.2.5 and assessed within the GenBank public database using the BLAST Search program for comparison and species identification.

\section{Cyp51A Gene Typing}

The whole cyp51A gene and its promoter were sequenced in both strands from all $A$. fumigatus strains with elevated MIC values, using five sets of primers: PA5 and PA7 (Mellado et al., 2001), AF306F and AF855R, AF766F and AF1330R, AF1179F and AF1709R, and AF1426F and AF2025R (Alanio et al., 2011).

The PCR mixture contained $5 \mu \mathrm{L}$ of DNA extract and $20 \mu \mathrm{L}$ of mix composed of $0.625 \mathrm{U}$ of GoTaq ${ }^{\circledR}$ Hot Start Polymerase (Promega), 1x Colorless GoTaq ${ }^{\circledR}$ Flexi Buffer (Promega), $2 \mathrm{mM}$ of $\mathrm{MgCl}_{2}$ (Promega), $0.8 \mathrm{mM}$ of dNTP mix (Eurobio), and $0.2 \mu \mathrm{M}$ of each primer. The amplification program consisted of $5 \mathrm{~min}$ at $94^{\circ} \mathrm{C}, 30$ cycles of $30 \mathrm{~s}$ at $94^{\circ} \mathrm{C}, 30 \mathrm{~s}$ at $58^{\circ} \mathrm{C}$, and $1 \mathrm{~min}$ at $72^{\circ} \mathrm{C}$, followed by a final step of $10 \mathrm{~min}$ at $72^{\circ} \mathrm{C}$.

Following purification and sequencing as described above, sequences of resistant strains were compared to the wild-type A. fumigatus sequence CM 237 (GenBank accession number AF338659), at http://blast.ncbi.nlm.nih.gov/Blast.cgi.

\section{Statistical Analysis}

Data analysis was performed using GraphPad PRISM ${ }^{\circledR}$ v.5.02 software. For continuous variables, the Mann-Whitney test was used. A $p$-value of 0.05 was considered statistically significant.

\section{RESULTS}

\section{Study Population}

One hundred and nineteen specimens were collected in the context of routine clinical follow-up from $87 \mathrm{CF}$ patients (sex ratio: 1.1), aged 4-59 years old (mean age: $26 \pm 13$ years), and included for both culture and PCR assays. Of the 87 patients, 37 $(42.5 \%)$ were receiving triazole therapy at the time of sampling, specifically itraconazole $(n=25)$, posaconazole $(n=11)$, or voriconazole $(n=1)$.

\section{Detection of Aspergillus in Sputum Samples}

As depicted in Table 1, A. fumigatus grew in 42 of the 119 sputum samples (35.3\%), corresponding to 33 distinct patients. The two in-house Af-mito and 28S PCRs were positive in 65 (54.6\%) and 68 samples (57.1\%), respectively. Only 37 and 38 of the 42 sputum samples grown with $A$. fumigatus yielded positive PCR results 
TABLE 1 | Aspergillus PCR results according to sputum culture results $(n=119)$.

\begin{tabular}{|c|c|c|c|c|c|}
\hline \multirow[t]{2}{*}{ Culture results } & \multicolumn{5}{|c|}{ Positive Aspergillus PCR assay results $n(\%)$} \\
\hline & Af mito PCR & $28 S$ PCR & Mycogenie ${ }^{\circledR}$ PCR & Aspergenius $^{\circledR}$ Af PCR & Aspergenius ${ }^{\circledR}$ Asp sp. PCR \\
\hline All $(n=119)$ & $65(54.6)$ & $68(57.1)$ & $64(53.8)$ & $57(47.9)$ & $64(53.8)$ \\
\hline \multicolumn{6}{|l|}{ Positive culture for Aspergillus } \\
\hline A. fumigatus $(n=42)$ & $37(88.1)$ & $38(90.5)$ & $31(73.8)$ & $33(78.6)$ & $35(83.3)$ \\
\hline Non-fumigatus Aspergillus species ${ }^{a}(n=5)$ & $2^{b}(40.0)$ & $2^{b}(40.0)$ & $2^{b}(40.0)$ & $2^{b}(40.0)$ & $3^{\mathrm{b}, \mathrm{c}}(60.0)$ \\
\hline Positive culture for other molds ${ }^{d}(n=19)$ & $2^{e}(10.5)$ & $3^{e}(15.8)$ & $3^{e}(15.8)$ & $1^{e}(5.3)$ & $2^{f}(10.5)$ \\
\hline Negative culture ${ }^{g}(n=55)$ & $26(47.3)$ & $27(49.1)$ & $30(53.6)$ & $23(41.8)$ & 26 (43.3) \\
\hline
\end{tabular}

${ }^{a}$ A. nidulans $(n=1)$, A. versicolor $(n=1)$, Aspergillus sp. $(n=1)$, A. terreus $(n=1), A$. flavus $(n=1)$. ${ }^{b}$ Samples grown simultaneously with A. fumigatus and flavus ( $\left.n=1\right)$, A. fumigatus and A. terreus $(n=1)$. ${ }^{c} A$. nidulans $(n=1)$. ${ }^{d}$ Scedosporium sp. $(n=6)$; Penicillium sp. $(n=8) ;$ Rasamsonia argillacea $(n=2)$; dematiaceous molds $(n=2)$; unidentified mold $(n=1) .{ }^{e}$ All were Scedosporium sp.. ${ }^{f}$ Scedosporium sp. $(n=1)$, Penicillium $(n=1)$ gYeasts were not taken into account. PCR, polymerase chain reaction.

with Af-mito and 28S PCR, respectively. Roughly similar results were recorded with the two commercial PCRs (Mycogenie ${ }^{\circledR}$ and Aspergenius $\left.{ }^{\circledR}\right)$, which amplified $64(53.8 \%)$ and 57 (47.9\%) of the total 119 samples, respectively.

Of note, the use of internal control for PCR inhibitors monitoring showed the presence of inhibitors to be prevalent in sputum samples. For in house-PCRs, 28 out of 119 (20\%) samples yielded a positive signal for Aspergillus detection after dilutions (up to 1:50).

Interestingly, all PCRs detected A. fumigatus in a large number of samples that were negative in culture. As many as $41.8 \%$ to $53.6 \%$ of the 55 negative culture samples were, in fact, positive with at least one of the four PCRs. Mycogenie ${ }^{\circledR}$ achieved the highest sensitivity in these samples, detecting 30/55 positive specimens (53.6\%), whereas the AsperGenius ${ }^{\circledR}$ PCR targeting A. fumigatus (Af) offered the lowest sensitivity (23/55, 41.8\%). The AsperGenius ${ }^{\circledR}$ Asp sp. assay was positive in $26 / 55$ negative culture samples (43.3\%), two of which tested positive exclusively for this target, suggesting that non-Aspergillus DNA was present in these samples.

None of the three sputum specimens grown with only non-A. fumigatus species yielded positive results with any of the four PCRs specifically targeting A. fumigatus. Conversely, Aspergenius ${ }^{\circledR}$ Asp sp. correctly detected A. nidulans, yet was negative for the sample grown with $A$. versicolor. Finally, as observed previously by our team, all the PCRs yielded cross-reaction, with three out of six specimens detected as positive for Scedosporium (Guegan et al., 2018).

\section{Resistance Screening Using Commercial PCR Assays}

As shown in Table 2, no cyp51A gene alterations were detected by Mycogenie ${ }^{\circledR}$ and Aspergenius ${ }^{\circledR}$ assay in the 57 and 64 sputum samples positive for A. fumigatus, respectively. However, Aspergenius $^{\circledR}$ assay correctly amplified the four regions of the cyp51A gene in only 20 of the 57 assessable specimens (35\%). Amplification success was variable and depended on the cyp51A target, with detection rates ranging from $38.6 \%$ (L98H region) to $56.1 \%$ (T289A region) (Table 2 ). This finding was probably linked to the low fungal burden in samples with incomplete cyp51A typing, as shown by the mean $C t$ values of
Af target, which were significantly higher in samples with failed amplification compared to others $(32.7 \pm 1.6$ vs. $34.1 \pm 1.6$, $p=0.005)$.

\section{Resistance Screening Using MIC Determination}

We were able to assess susceptibility to triazole drugs for 41/42 A. fumigatus isolates. As presented in Figure 1, five isolates presented a resistance profile (12.2\%) with high ITC MIC $(\geq 32 \mathrm{mg} / \mathrm{L})$. Of these five, collected from five distinct patients, three displayed cross-resistance to VRC, with high MICs ranging from 8 to $>32 \mathrm{mg} / \mathrm{L}$. Susceptibility to POS was also reduced in four of the five strains (MICs from 4 to $>32 \mathrm{mg} / \mathrm{L}$ ).

\section{Cyp51A Gene Sequencing of Resistant A. fumigatus Isolates and Occurrence During Patient Follow Up}

The whole cyp51A gene of the five resistant isolates was further sequenced to identify the mechanism responsible for resistance. Three of the five displayed cyp51A gene alterations (Table 3). One $\mathrm{L} 98 \mathrm{H}$ mutation (associated with a $34 \mathrm{bp}$ tandem repeat in the promoter) was found in a pan-azole-resistant isolate. Surprisingly, the sputum sample from which this strain was cultured did not yield a detection of cyp51A mutation with any PCR assay (Mycogenie ${ }^{\circledR}$, Aspergenius ${ }^{\circledR}$ ). M220K and G54R mutations were both observed in strains with ITC and POS combined resistance.

The characteristics of patients colonized with resistant strains are depicted in Figure 2. All five had been receiving longterm itraconazole therapy for periods ranging from 11 months (Patient 1 ) to over 10 years (Patient 4 ) prior to sampling. No correlation was found between patient age or duration of triazole exposure and $c y p 51 A$ genotype.

\section{DISCUSSION}

The burden of Aspergillus infections and sensitization is high among fungal diseases, particularly in the context of chronic pulmonary diseases (Gangneux et al., 2016). The emergence of triazole resistance in A. fumigatus has fuelled interest in 
TABLE 2 | Detection of cyp51A mutation using Mycogenie ${ }^{\circledR}$ and Aspergenius ${ }^{\circledR}$ assays.

\begin{tabular}{|c|c|c|c|c|c|c|}
\hline \multicolumn{2}{|c|}{ PCR assay } & \multicolumn{5}{|c|}{ Number of positive samples (\%) for } \\
\hline & & A. fumigatus & $\mathbf{T R}_{34}$ & L98H & Y121F & T289A \\
\hline \multirow[t]{2}{*}{ AsperGenius ${ }^{\oplus}$} & Target amplification ${ }^{a}$ & $57(47.9)$ & 25/57 (43.9) & 22/57 (38.6) & $30 / 57(52.6)$ & $32 / 57(56.1)$ \\
\hline & Detection of mutated allele ${ }^{b}$ & NA & $0 / 25$ & $0 / 21$ & $0 / 30$ & $0 / 32$ \\
\hline Mycogenie ${ }^{\circledR}$ & Detection of mutated allele & $64(53.8)$ & $0 / 64$ & $0 / 64$ & NA & NA \\
\hline
\end{tabular}

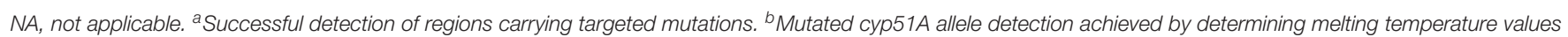
from $T_{3}, L 98 H, Y 121 F$, and T289A region amplicons.

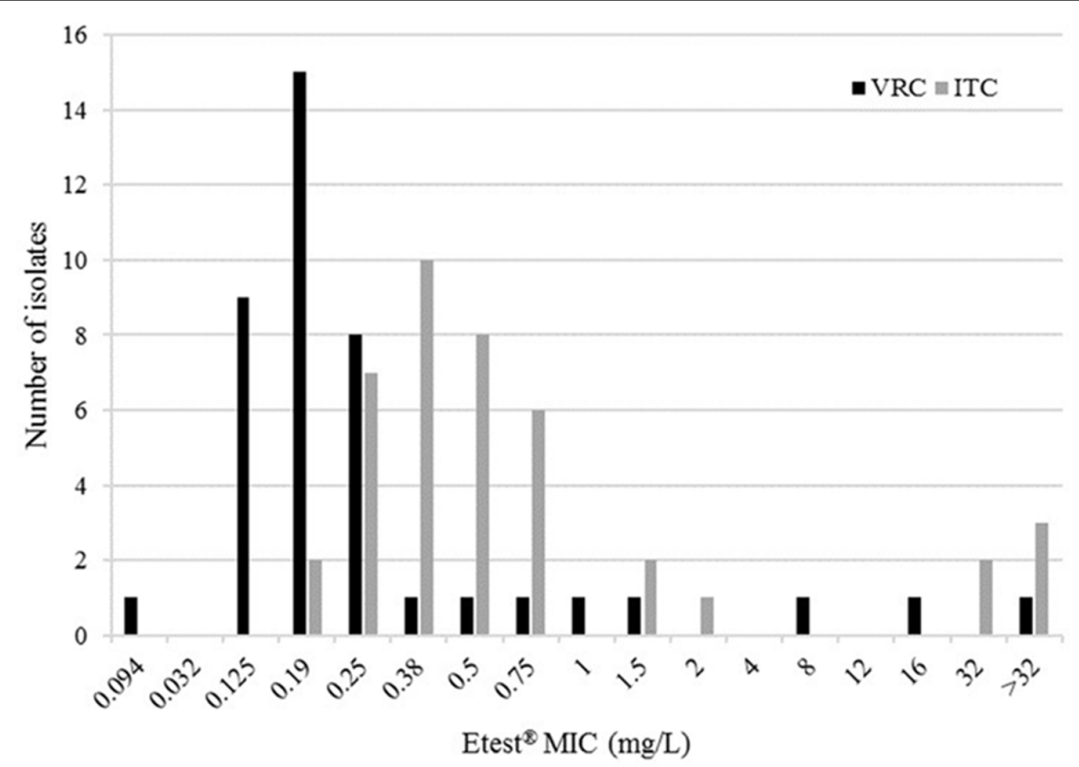

FIGURE 1 | Distribution of itraconazole (ITC) and voriconazole (VRC) minimum inhibitory concentrations (MICs) of 41 Aspergillus fumigatus strains using Etest ${ }^{\circledR}$.

molecular screening of clinical specimens. Here, we investigated prospectively whether using two commercial PCR assays was effective in (i) detecting Aspergillus in sputum samples from CF patients compared to culture or in-house PCRs, and (ii) in typing azole resistance.

Aspergillus fumigatus was the most frequent fungus isolated from CF sputum, with $35.3 \%$ of samples testing positive. PCR offered much higher sensitivity than culture, with over $40 \%$ of

TABLE 3 | Minimum inhibitory concentration (MIC) and cyp51A sequencing of azole-resistant isolates.

\begin{tabular}{|c|c|c|c|c|c|}
\hline \multirow[t]{2}{*}{ Patient $n^{\circ}$} & \multicolumn{2}{|c|}{ cyp51a mutation (typing) } & \multicolumn{3}{|c|}{ MIC Etest $^{\circledR}$ (mg/L) } \\
\hline & $\begin{array}{l}\text { Nucleotide } \\
\text { sequence }\end{array}$ & $\begin{array}{c}\text { Amino acid } \\
\text { sequence }\end{array}$ & VRC & ITC & POS \\
\hline 1 & None & None & 16 & 32 & 0.094 \\
\hline 2 & t293a & $\mathrm{TR}_{34} / \mathrm{L} 98 \mathrm{H}$ & $>32$ & $>32$ & $>32$ \\
\hline 3 & t659a & M220K & 1.5 & $>32$ & $>32$ \\
\hline 4 & g160a & G54R & 0.25 & $>32$ & $>32$ \\
\hline 5 & None & None & 8 & 32 & 4 \\
\hline
\end{tabular}

MIC, minimum inhibitory concentration; VRC, voriconazole; ITC, itraconazole; POS, posaconazole. negative cultures yielding positive results with at least one PCR assay. There is very little data on PCR efficacy in CF sputum analyses in the literature, and our results reinforced the findings of a previous study that revealed considerable discrepancies between culture and PCR sensitivity (33\% vs. $73 \%$, respectively) (Baxter et al., 2011). We performed a standardized sputum homogenization, as this process has been shown to be crucial for these analyses (Baxter et al., 2011). The viscous nature and complex matrix of CF sputum can be responsible for inhibition and impaired detection. We thus introduced internal checks to monitor sample inhibition and systematically performed sample dilutions for in-house PCRs to minimize this phenomenon. More than 20\% were found to contain PCR inhibitors. Exposure to antifungals may also contribute to limited performances of culturing but also molecular detection of Aspergillus. In the context of invasive aspergillosis, we previously showed the worth of molecular detection of Aspergillus in intensive care unit patients compared to patients that benefit from antifungal prophylaxis in hematology units (Guegan et al., 2018).

Scedosporium is usually considered the second most prevalent filamentous fungus in CF. In our study, we recorded a significant incidence of Scedosporium isolates (6/119), producing three positive PCR results. These results question an apparent lack of 


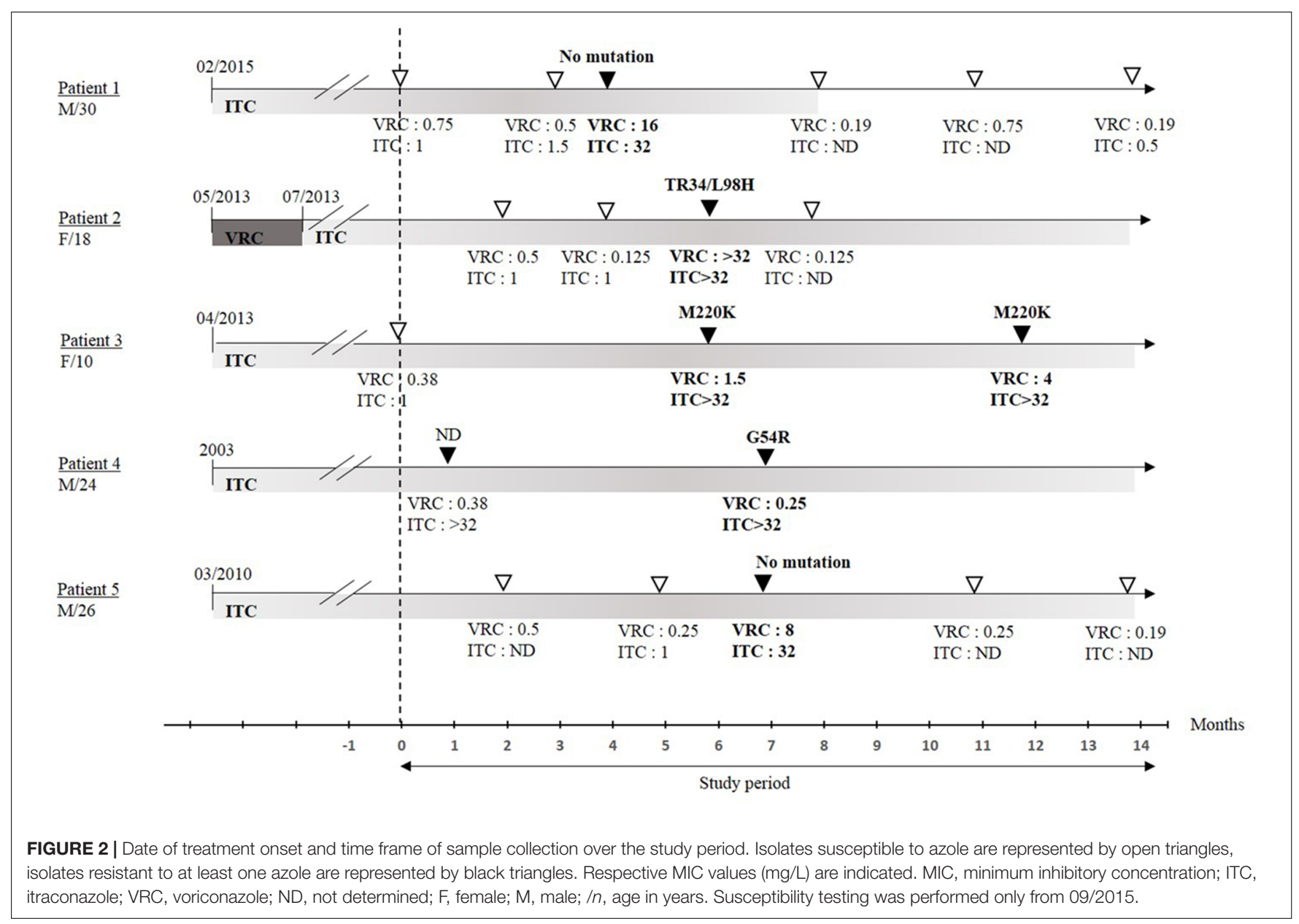

specificity of the Aspergillus PCR assay regarding Scedosporium species. Three isolates were sequenced using the ITS1-5.8S-ITS2 gene. No species relationship was confirmed, as all strains were identified as part of Scedosporium apiospermum complex (data not shown).

While some studies have identified associations between Aspergillus isolation in sputum samples and the risk of pulmonary exacerbations or deteriorating respiratory function (Amin et al., 2010), the clinical relevance of PCRs in these specimens has not yet been assessed. The question remains, for example, of whether DNA fungal detection is associated with respiratory disease or is only a marker of colonization (Jones et al., 2014). In our cohort, the detection of serological markers was completed within a 3-month period surrounding sputum sampling for 26 of the 27 patients producing positive PCRs but negative cultures. Aspergillus antibodies or precipitins were detected in nine of them (34.6\%, data not shown), indicating chronic exposure. Overall, the high sensitivity of PCR on sputum could contribute to more effective grading of Aspergillus disease in CF patients together with clinical signs and other biological markers, as proposed by Baxter et al. (2013).

The optimal therapeutic management of $\mathrm{CF}$ patients chronically colonized with Aspergillus is still a matter of debate. There is no consensus on the use of triazole components when A. fumigatus is detected in respiratory samples (Burgel et al., 2016). However, the emergence of A. fumigatus strains resistant to azole drugs has to be taken into account for clinical management. Here we observed reduced susceptibility to itraconazole in 5/41 A. fumigatus isolates (12.2\%) similar to that already reported (Morio et al., 2012). The growing incidence of resistant fungi in clinical specimens is currently driving the development of new molecular approaches for rapid resistance screening directly on respiratory samples. As far as we know, this study was the first prospective evaluation of commercial multiplex PCRs to monitor triazole resistance in CF samples. These assays did not enable us to detect any hotspot mutation markers in the 57 and 64 sputum samples amplified with Aspergenius $^{\circledast}$ Af PCR and Mycogenie ${ }^{\circledast}$ PCR, respectively. It should be noted that, in the respiratory samples from British patients with CPA, high azole resistance rates was reported using PCR (around 50\%), while the cultures remained negative (Denning et al., 2011).

Globally, the sensitivity of marketed cyp51A PCR assays was low, primarily due to there being only a single copy of the gene. In contrast, culture isolation of resistant Aspergillus enabled us to sequence cyp51A. Of the five resistant isolates, three displayed $\mathrm{TR}_{34} / \mathrm{L} 98 \mathrm{H}, \mathrm{M} 220$ or G54 mutations that have already been linked to azole resistance in CF patients. Moreover, 
strains without any cyp51A alterations have been shown to be an emerging concern, suggesting the possibility there are other mechanisms responsible for triazole resistance (RiveroMenendez et al., 2016).

Finally, PCR achieved much higher positivity in its detection of Aspergillus than culture, regardless of the method used (in-house or marketed). As for multiplex PCR, also able to detect cyp51A mutations, the presence of this gene in a single copy limits the sensitivity of a molecular approach compared to culture. There are, however, two potential limits to the resistance screening method based on MIC determination that should be discussed. Firstly, MIC is usually determined using a single colony in routine practice, yet there has been biodiversity reported within the same sputum. For example, a previous study reported up to $28 \%$ of CF patients presented complex colonization patterns containing various genotypes which succeeded each other, regardless of their antifungal susceptibility (de Valk et al., 2009). In our study, of the five patients colonized with resistant strains, only two produced several consecutive cultures growing with resistant strains (patients 3 and 4, Figure 2), despite no drug switches being performed between samplings. To overcome this potential inaccuracy, the use of a selective medium supplemented with antifungals for resistance detection from primary culture is currently spreading in routine practice, although there are no studies as yet reporting their relevance in CF samples (Hamprecht et al., 2017). Secondly, while there are few strains that show low MICs to itraconazole and resistance to voriconazole, itraconazole should be the preferred drug for measuring in vitro MIC due to the

\section{REFERENCES}

Alanio, A., Sitterle, E., Liance, M., Farrugia, C., Foulet, F., Botterel, F., et al. (2011). Low prevalence of resistance to azoles in Aspergillus fumigatus in a French cohort of patients treated for haematological malignancies. J. Antimicrob. Chemother. 66, 371-374. doi: 10.1093/jac/dkq450

Alcazar-Fuoli, L., and Mellado, E. (2013). Ergosterol biosynthesis in Aspergillus fumigatus: its relevance as an antifungal target and role in antifungal drug resistance. Front. Microbiol. 3:439. doi: 10.3389/fmicb.2012.00439

Amin, R., Dupuis, A., Aaron, S. D., and Ratjen, F. (2010). The effect of chronic infection with Aspergillus fumigatus on lung function and hospitalization in patients with cystic fibrosis. Chest 137, 171-176. doi: 10.1378/chest.09-1103

Baxter, C. G., Dunn, G., Jones, A. M., Webb, K., Gore, R., Richardson, M. D., et al. (2013). Novel immunologic classification of aspergillosis in adult cystic fibrosis. J. Allergy Clin. Immunol. 132, 560.e10-566.e10. doi: 10.1016/j.jaci.2013. 04.007

Baxter, C. G., Jones, A. M., Webb, K., and Denning, D. W. (2011). Homogenisation of cystic fibrosis sputum by sonication - An essential step for Aspergillus PCR. J. Microbiol. Methods 85, 75-81. doi: 10.1016/j.mimet.2011.01.024

Borman, A. M., Palmer, M. D., Delhaes, L., Carrère, J., Favennec, L., Ranque, S., et al. (2010). Lack of standardization in the procedures for mycological examination of sputum samples from CF patients: a possible cause for variations in the prevalence of filamentous fungi. Med. Mycol. 48, S88-S97. doi: 10.3109/13693786.2010.511287

Bretagne, S., Costa, J.-M., Marmorat-Khuong, A., Poron, F., Cordonnier, C., Vidaud, M., et al. (1995). Detection of Aspergillus species DNA in bronchoalveolar lavage samples by competitive PCR. J. Clin. Microbiol. 33, 1164-1168.

Burgel, P.-R., Baixench, M.-T., Amsellem, M., Audureau, E., Chapron, J., Kanaan, R., et al. (2012). High prevalence of azole-resistant Aspergillus discrepancies between resistance expression against the various azoles. However, this procedure may miss some exceptional strains resistant to voriconazole despite low itraconazole MIC.

\section{ETHICS STATEMENT}

This study was conducted in accordance with the Declaration of Helsinki and national and institutional standards. It was approved by the local 'Rennes Ethics Committee'. No supplementary samples were drawn and investigations were considered part of routine clinical practice. However, patients or next of kin was informed of their inclusion in this study and could refuse to participate.

\section{AUTHOR CONTRIBUTIONS}

J-PG and FR-G designed, performed, and wrote the manuscript. HG and SC performed the analysis and wrote the manuscript. CB and ED contributed to the analysis of data.

\section{ACKNOWLEDGMENTS}

The authors want to thank Pfizer France for the unrestricted grant ATCF (Antifungal Therapy during Cystic Fibrosis) and the CHU de Rennes for English editing service. HG thanks the CHU de Rennes for manuscript editing.

fumigatus in adults with cystic fibrosis exposed to itraconazole. Antimicrob. Agents Chemother. 56, 869-874. doi: 10.1128/AAC.05077-11

Burgel, P. R., Paugam, A., Hubert, D., and Martin, C. (2016). Aspergillus fumigatus in the cystic fibrosis lung: pros and cons of azole therapy. Infect. Drug Resist. 9, 229-238. doi: 10.2147/IDR.S63621

Challier, S., Boyer, S., Abachin, E., and Berche, P. (2004). Development of a serum-based Taqman real-time PCR assay for diagnosis of invasive aspergillosis. J. Clin. Microbiol. 42, 844-846. doi: 10.1128/JCM.42.2.844-846. 2004

Chong, G. L., van de Sande, W. W., Dingemans, G. J., Gaajetaan, G. R., Vonk, A. G., Hayette, M.-P., et al. (2015). Validation of a new Aspergillus real-time PCR assay for direct detection of Aspergillus and azole resistance of Aspergillus fumigatus on bronchoalveolar lavage fluid. J. Clin. Microbiol. 53, 868-874. doi: 10.1128/JCM.03216-14

Comacle, P., Belaz, S., Jegoux, F., Ruaux, C., Le Gall, F., Gangneux, J.-P., et al. (2016). Contribution of molecular tools for the diagnosis and epidemiology of fungal chronic rhinosinusitis. Med. Mycol. 54, 794-800. doi: 10.1093/mmy/ myw041

Dannaoui, E., Gabriel, F., Gaboyard, M., Lagardere, G., Audebert, L., Quesne, G., et al. (2017). Molecular diagnosis of invasive aspergillosis and detection of azole resistance by a newly commercialized PCR Kit. J. Clin. Microbiol. 55, 3210-3218. doi: 10.1128/JCM.01032-17

de Valk, H. A., Klaassen, C. H., Yntema, J. B., Hebestreit, A., Seidler, M., Haase, G., et al. (2009). Molecular typing and colonization patterns of Aspergillus fumigatus in patients with cystic fibrosis. J. Cyst. Fibros. 8, 110-114. doi: 10.1016/j.jcf.2008.10.003

Denning, D. W., Park, S., Lass-Florl, C., Fraczek, M. G., Kirwan, M., Gore, R., et al. (2011). High-frequency triazole resistance found in nonculturable Aspergillus fumigatus from lungs of patients with chronic fungal disease. Clin. Infect. Dis. 52, 1123-1129. doi: 10.1093/cid/cir179 
European Committee on Antimicrobial Susceptibility Testing [Eucast] (2017). Antifungal Agents-Breakpoint tables for interpretation of MICs, version 8.1. Available at: http://www.eucast.org/clinical_breakpoints/

Gangneux, J.-P., Bougnoux, M.-E., Hennequin, C., Godet, C., Chandenier, J., Denning, D. W., et al. (2016). An estimation of burden of serious fungal infections in France. J. Med. Mycol. 26, 385-390. doi: 10.1016/j.mycmed.2016. 11.001

Glass, N. L., and Donaldson, G. C. (1995). Development of primer sets designed for use with the PCR to amplify conserved genes from filamentous ascomycetes. Appl. Environ. Microbiol. 61, 1323-1330.

Guegan, H., Robert-Gangneux, F., Camus, C., Belaz, S., Marchand, T., Baldeyrou, M., et al. (2018). Improving the diagnosis of invasive aspergillosis by the detection of Aspergillus in broncho-alveolar lavage fluid: comparison of non-culture-based assays. J. Infect. 76, 196-205. doi: 10.1016/j.jinf.2017.11.011

Hamprecht, A., Morio, F., Bader, O., Le Pape, P., Steinmann, J., and Dannaoui, E. (2017). Azole resistance in Aspergillus fumigatus in patients with cystic fibrosis: a matter of concern? Mycopathologia 183, 151-160. doi: 10.1007/s11046-0170162-4

Jones, A. M., Horsley, A., and Denning, D. W. (2014). What is the importance of classifying Aspergillus disease in cystic fibrosis patients? Expert Rev. Respir. Med. 8, 389-392. doi: 10.1586/17476348.2014.915751

Mellado, E., Diaz-Guerra, T. M., Cuenca-Estrella, M., and Rodriguez-Tudela, J. L. (2001). Identification of two different 14- sterol demethylase-related genes (cyp51A and cyp51B) in Aspergillus fumigatus and Other Aspergillus species. J. Clin. Microbiol. 39, 2431-2438. doi: 10.1128/JCM.39.7.2431-2438.2001

Morio, F., Aubin, G. G., Danner-Boucher, I., Haloun, A., Sacchetto, E., GarciaHermoso, D., et al. (2012). High prevalence of triazole resistance in Aspergillus fumigatus, especially mediated by TR/L98H, in a French cohort of patients with cystic fibrosis. J. Antimicrob. Chemother. 67, 1870-1873. doi: 10.1093/jac/ dks160

Pihet, M., Carrere, J., Cimon, B., Chabasse, D., Delhaes, L., Symoens, F., et al. (2009). Occurrence and relevance of filamentous fungi in respiratory secretions of patients with cystic fibrosis - a review. Med. Mycol. 47, 387-397. doi: 10.1080/ 13693780802609604

Rivero-Menendez, O., Alastruey-Izquierdo, A., Mellado, E., and CuencaEstrella, M. (2016). Triazole resistance in Aspergillus spp.: a Worldwide Problem? J. Fungi 2:21. doi: 10.3390/jof2030021

Spiess, B., Postina, P., Reinwald, M., Cornely, O. A., Hamprecht, A., Hoenigl, M., et al. (2014). Incidence of Cyp51A key mutations in Aspergillus fumigatusA study on primary clinical samples of immunocompromised patients in the period of 1995-2013. PLoS One 9:e103113. doi: 10.1371/journal.pone.0103113
Spiess, B., Seifarth, W., Merker, N., Howard, S. J., Reinwald, M., Dietz, A., et al. (2012). Development of novel PCR assays to detect azole resistance-mediating mutations of the Aspergillus fumigatus cyp51A gene in primary clinical samples from neutropenic patients. Antimicrob. Agents Chemother. 56, 3905-3910. doi: 10.1128/AAC.05902-11

Stevens, D. A., Moss, R. B., Kurup, V. P., Knutsen, A. P., Greenberger, P., Judson, M. A., et al. (2003). Allergic bronchopulmonary aspergillosis in cystic fibrosisstate of the art: cystic fibrosis foundation consensus conference. Clin. Infect. Dis. 37, S225-S264.

van der Linden, J. W., Snelders, E., Arends, J. P., Daenen, S. M., Melchers, W. J., and Verweij, P. E. (2010). Rapid diagnosis of azole-resistant Aspergillosis by Direct PCR using tissue specimens. J. Clin. Microbiol. 48, 1478-1480. doi: 10.1128/JCM.02221-09

van der Linden, J. W., Snelders, E., Kampinga, G. A., Rijnders, B. J., Mattsson, E., Debets-Ossenkopp, Y. J., et al. (2011). Clinical implications of azole resistance in Aspergillus fumigatus, the Netherlands, 2007-2009. Emerg. Infect. Dis. 17, 1846-1854. doi: 10.3201/eid1710.110226

Verweij, P. E., Chowdhary, A., Melchers, W. J. G., and Meis, J. F. (2016). Azole resistance in Aspergillus fumigatus: Can we retain the Clinical Use of MoldActive Antifungal Azoles? Clin. Infect. Dis. 62, 362-368. doi: 10.1093/cid/ civ885

White, P. L., Posso, R. B., and Barnes, R. A. (2015). Analytical and clinical evaluation of the pathonostics aspergenius assay for detection of invasive aspergillosis and resistance to azole antifungal drugs during testing of serum samples. J. Clin. Microbiol. 53, 2115-2121. doi: 10.1128/JCM. 00667-1

Conflict of Interest Statement: J-PG received a grant from Pfizer France but states that they had no influence over the research and its conclusions.

The other authors declare that the research was conducted in the absence of any commercial or financial relationships that could be construed as a potential conflict of interest.

Copyright (c) 2018 Guegan, Chevrier, Belleguic, Deneuville, Robert-Gangneux and Gangneux. This is an open-access article distributed under the terms of the Creative Commons Attribution License (CC BY). The use, distribution or reproduction in other forums is permitted, provided the original author(s) and the copyright owner are credited and that the original publication in this journal is cited, in accordance with accepted academic practice. No use, distribution or reproduction is permitted which does not comply with these terms. 